LVVX ${ }^{\circledR}$ (fluvoxomine maleate) Tobleis

Brief Summary (For full Prescribing Informotion refer to pocknge insert.)

INDICATONS AND USAGE

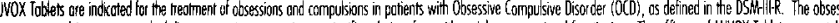

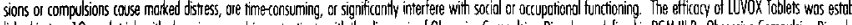

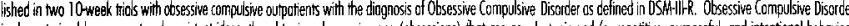

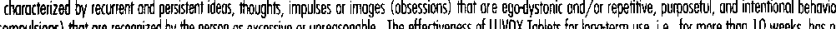

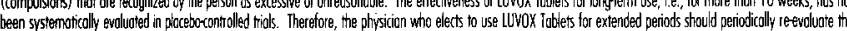
CONTHRANDichtions

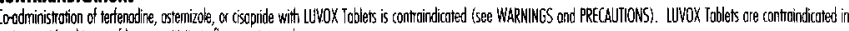
potients with o history of hppesensitivity to flusoxamine miceats.

WARNIIIS

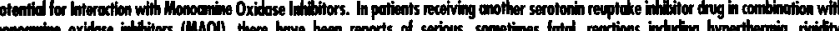

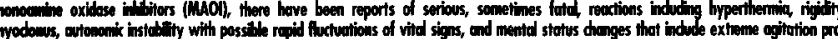

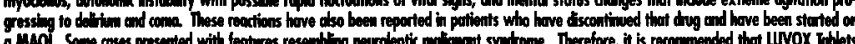

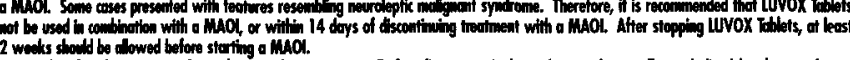

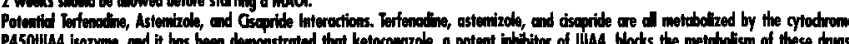

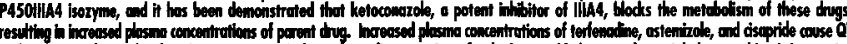

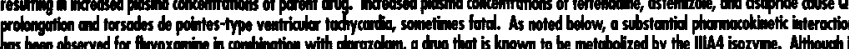

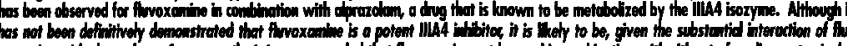

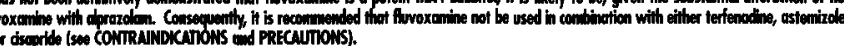

\section{Othor Poientialy limportani Dreng in terections}

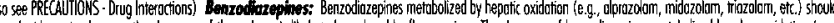

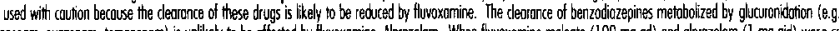

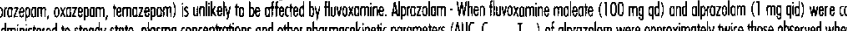

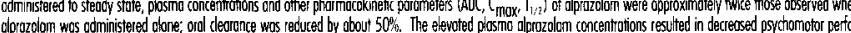
mance ond memory. This interccion, which has not been investigated using higher doses of fluvoxamine, moy be more pronounced if a $300 \mathrm{my}$ dally cose is co-admiris

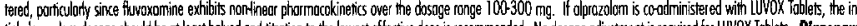

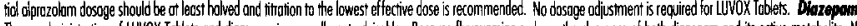

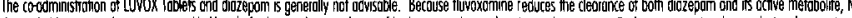

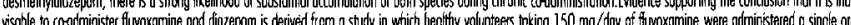

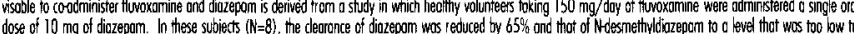

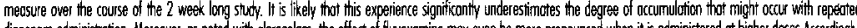

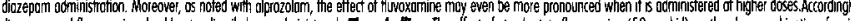

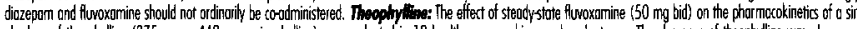
gle dose of theophylline ( $375 \mathrm{mg}$ os $442 \mathrm{mg}$ amirophyline) was evolucted in 12 heolthy nonsmoking, mole volunteers. The clecrance of theophylline wos decreased

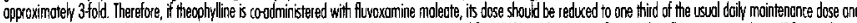

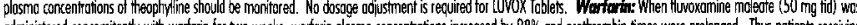

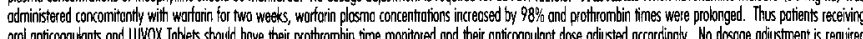

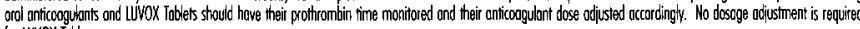
PRECAuITlOats

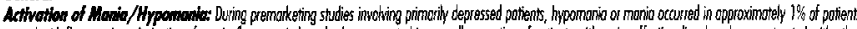

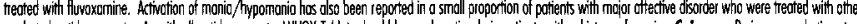

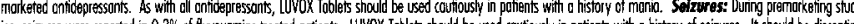

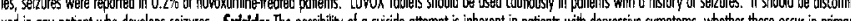

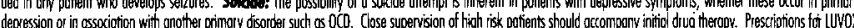

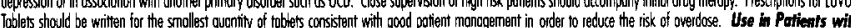

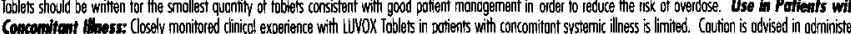

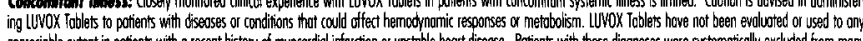

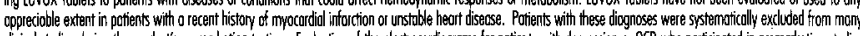

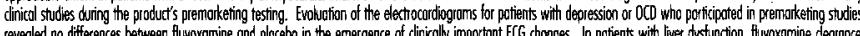
reveded no differences between fluvoxomine ond plocebo in the emergence of diricolly importtont $E[G$ chonges. In potients with liver dystunction,

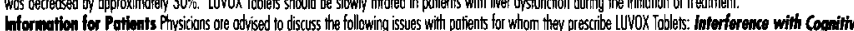

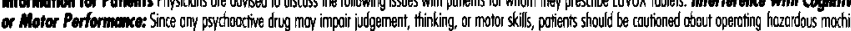

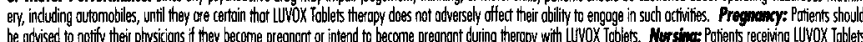

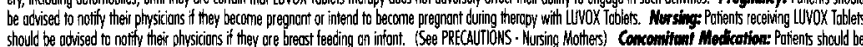

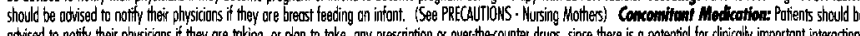

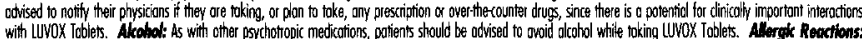

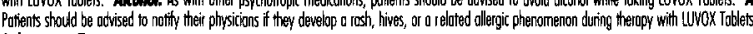

\section{Leborotory Tosts}

\section{Drug lateroctions}

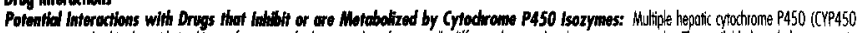

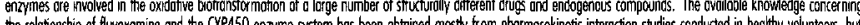
se elo

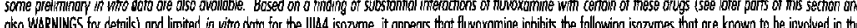

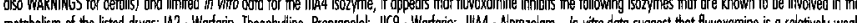

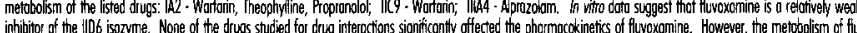

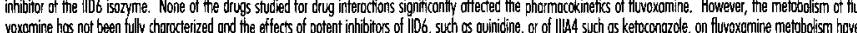

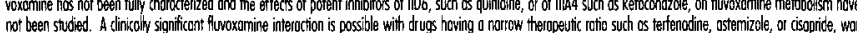

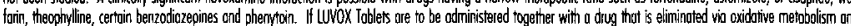

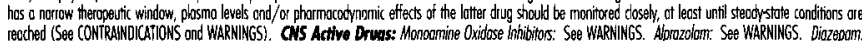

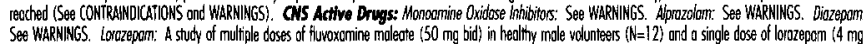

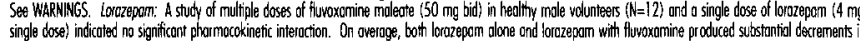

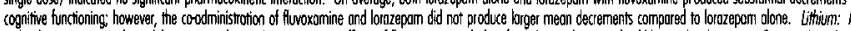
with other serolonergic drugs, ithium mey enhonce the serotoreegic effects of fuwoxomine and, therefore, the combiration should be ssed with coution. Seizues hove been

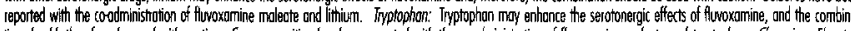

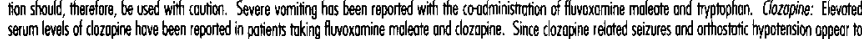

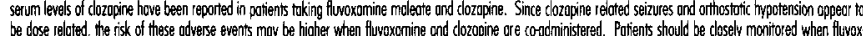

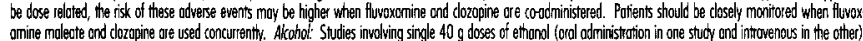

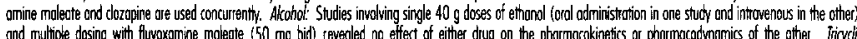

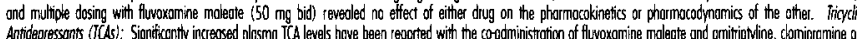

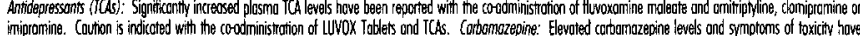

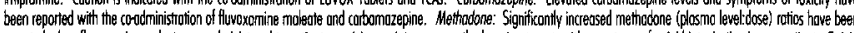

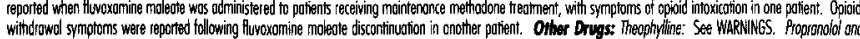

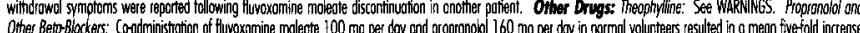

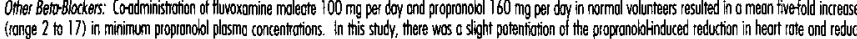

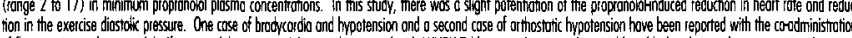

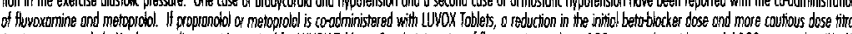

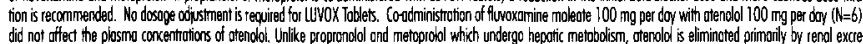

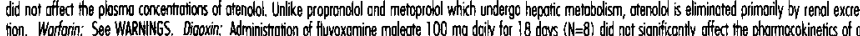

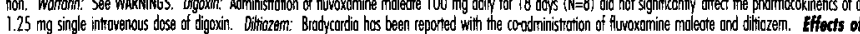

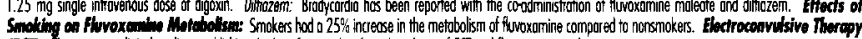

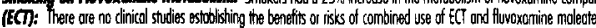

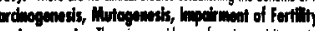

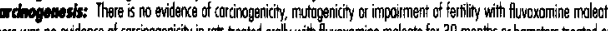

(t)

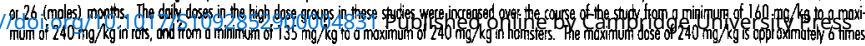

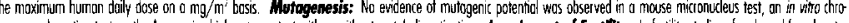

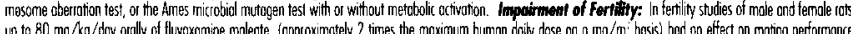
ip $1080 \mathrm{mg} / \mathrm{kg} / \mathrm{dgy}$ ordlly of fluvoxom

Pregnancy

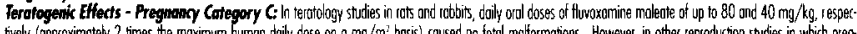

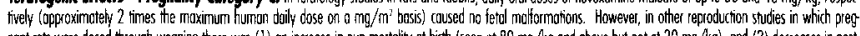

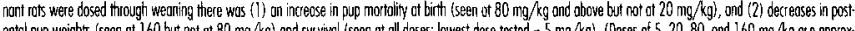

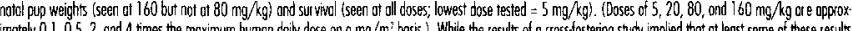

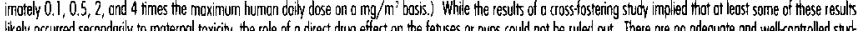

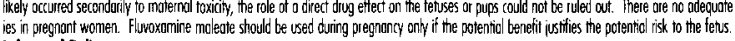

Laber and Delivery

The effect of hluroxon

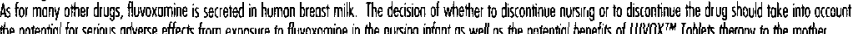
Pediatric Use

Solety and eftectiveness of LUMOX Tablets in indiriduals telaw 18 yeors of oge have not teen establishet.

Geriatric Use

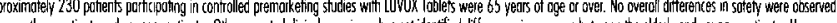

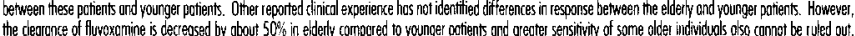

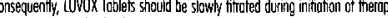

ADVERSE REACTIONS

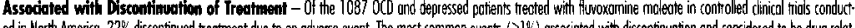

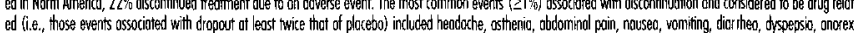
in, somnolence, irsomnio, nervousness, dizziness, ogitotion, anxiety, and dy mouth.

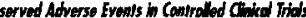

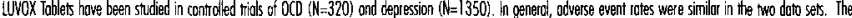

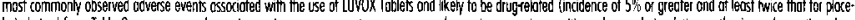

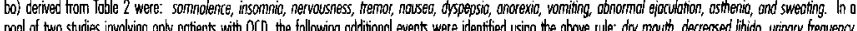

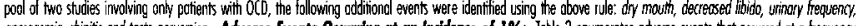

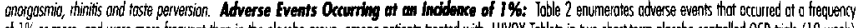

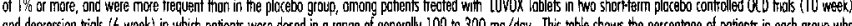

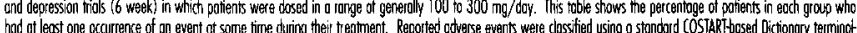

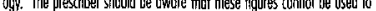

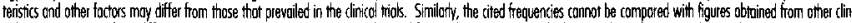

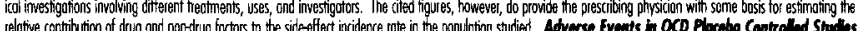

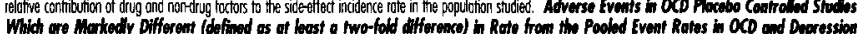

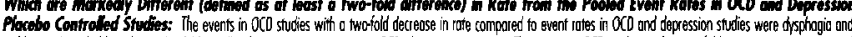

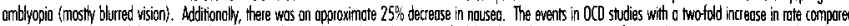

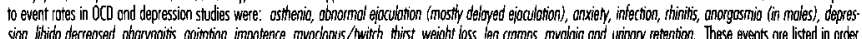

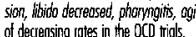

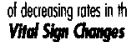

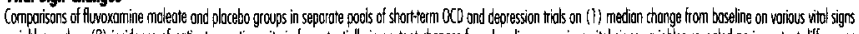
between find on (2) inidence of potientr meth

\title{
laboratory Changes
}

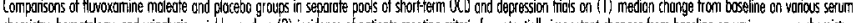

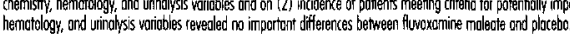

FCG Chager

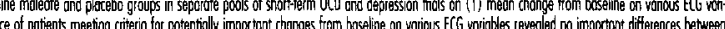
chles ond on (2) incidence of potient

Thlo 2: TREATMENT-EMERGENT ADVERSE EVENT INCIDENCE RAIIS BY BODY SYSTEM IN OCD AND DEPRESSIOH POPULATONS CO

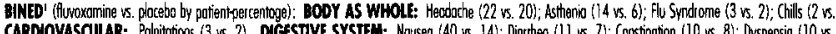

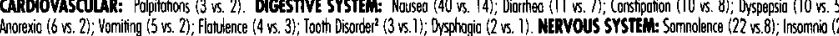

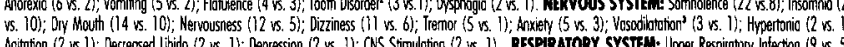

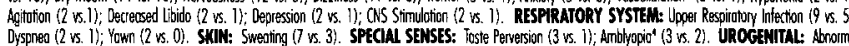

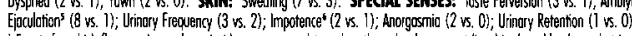

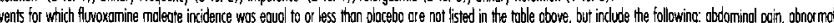

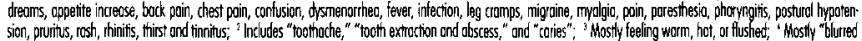

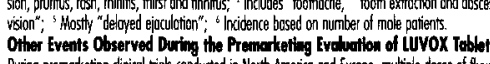

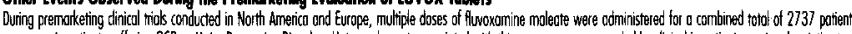

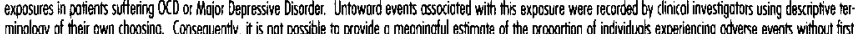

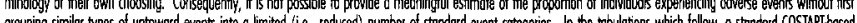

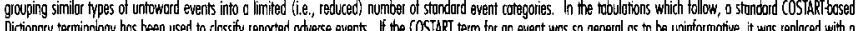

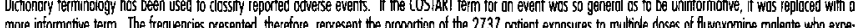

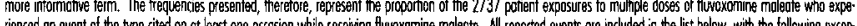

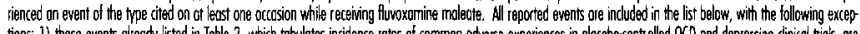

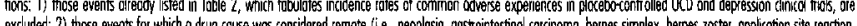

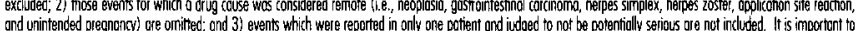

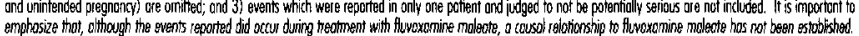

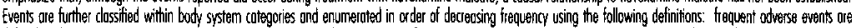
defined os those ccauring on one or more occasions in of least $1 / 100$ potients, infequent odverse events ore those eccuring between $1 / 100$ ond $1 / 1000$ potients; ond

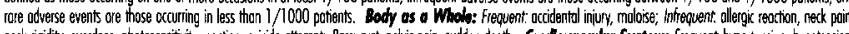

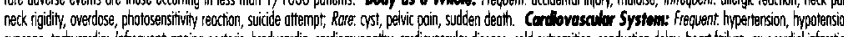

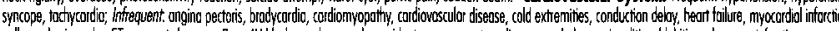

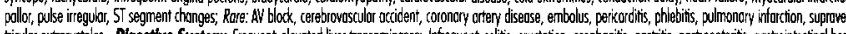

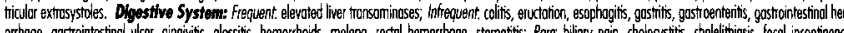

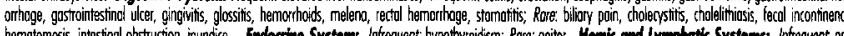

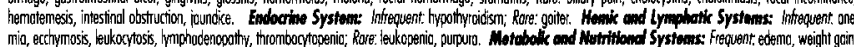

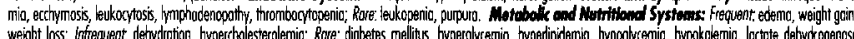

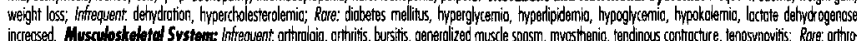

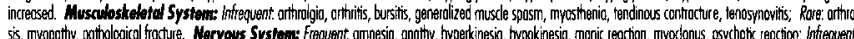

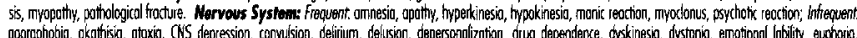

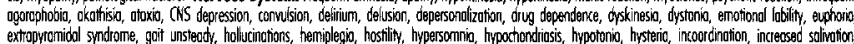

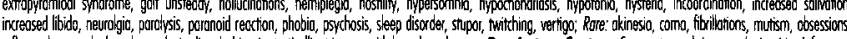

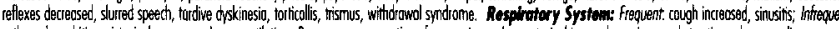

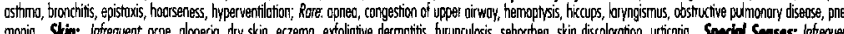

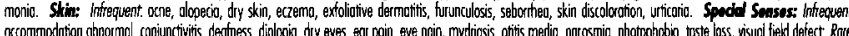

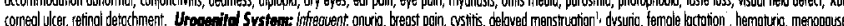

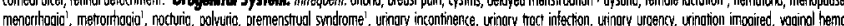

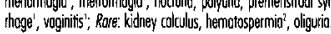

1 Bosed on the number of femoles; 2 Bosed on the nuriter of moles.

Norrus Postinumkethy Reports

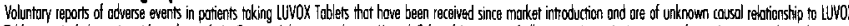

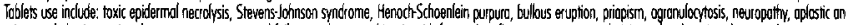

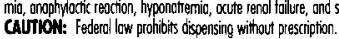

Reference: 1. Data on file. Solvay Phammacuticals. bic. 


\section{ESTABLISHIED THIERAPY FOR OCD}

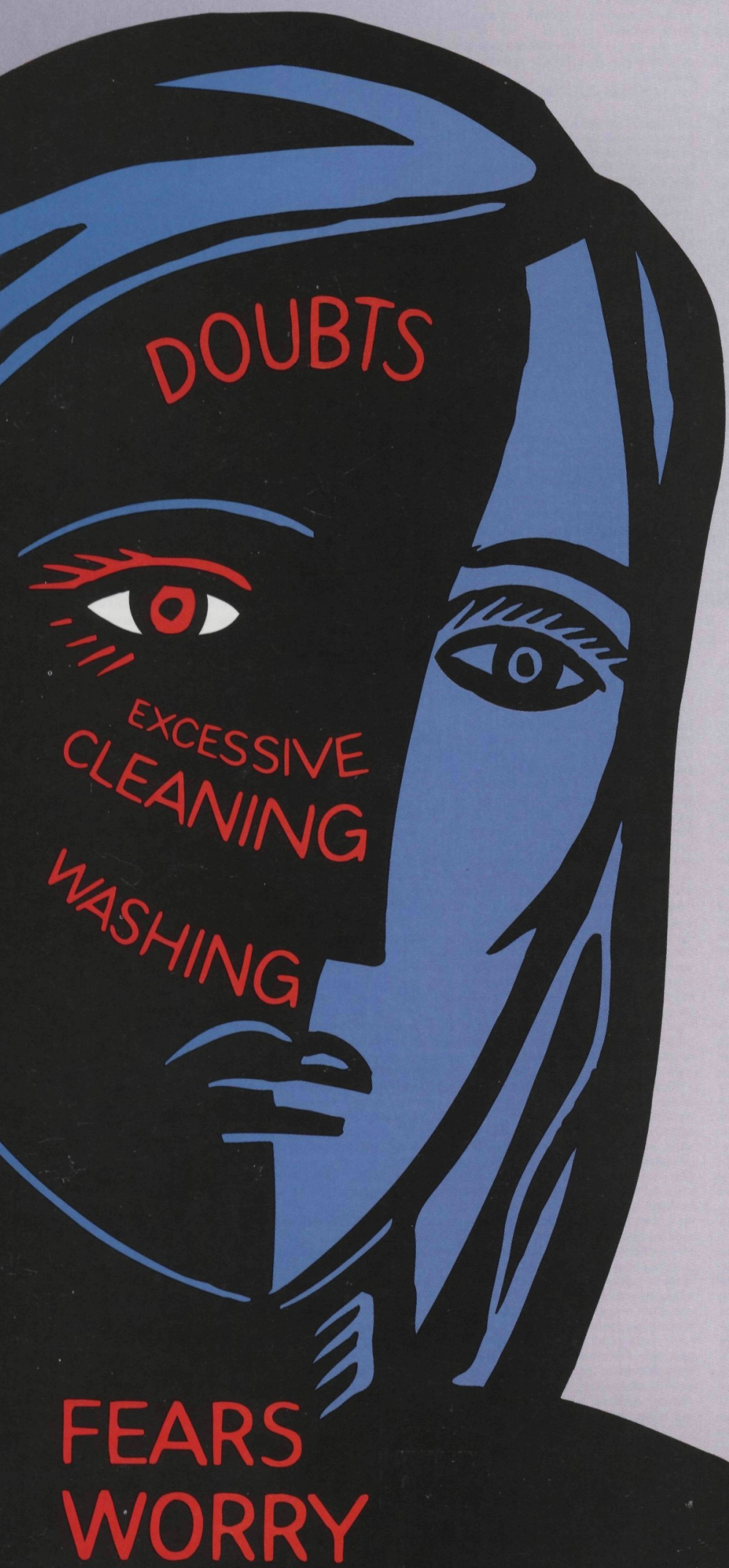

\section{EFFECTIVE CONTROL OF OBSESSIONS AND COMPULSIONS ${ }^{1 *}$}

\section{LOW INCIDENCE OF AGITATION \\ ( $2 \%$ vs $1 \%$ for placebo)}

\section{LOW INCIDENCE OF SEXUAL DYSFUNCTION}

* LUVOX ${ }^{\circledast}$ Tablets $v$ placebo: decreased libido $2 \%$ vs $1 \%$; delayed ejaculation $8 \%$ vs $1 \%$; anorgasmia $2 \%$ vs $0 \%$; impotence $2 \%$ vs $1 \%$

\section{FAVORABLE SAFETY PROFILE}

* Relatively low incidence of anticholinergic side effects in controlled trials of OCD and depression, LUVOX ${ }^{\circledast}$ Tablets vs placebo ${ }^{1}$ : dizziness $11 \%$ vs $6 \%$; constipation $10 \%$ vs $8 \%$; dry mouth $14 \%$ vs $10 \%$

* The most commonly observed adverse events compared to placebo were somnolence $22 \%$ vs $8 \%$, insomnia $21 \%$ vs $10 \%$, nervousness $12 \%$ vs $5 \%$, nausea $40 \%$ vs $14 \%$, abnormal ejaculation $8 \%$ vs $1 \%$, asthenia $14 \%$ vs $6 \%{ }^{1}$

* Concomitant use of LUVOX ${ }^{\circledR}$ Tablets and monoamine oxidase inhibitors is not recommended

\section{FLEXIBLE DOSING}

Initial Dose: $50 \mathrm{mg}$ once a day HS Dose Range: 100 to 300 mg/day

\section{COMPREHENSIVE SAFETY DATABASE}

(Worldwide Exposure for Reporting Overdose $\left.{ }^{*}\right)^{1}$

* Data from 40 countries

* Over 12 million patients treated

* More than 37,000 patients studied in clinical trials

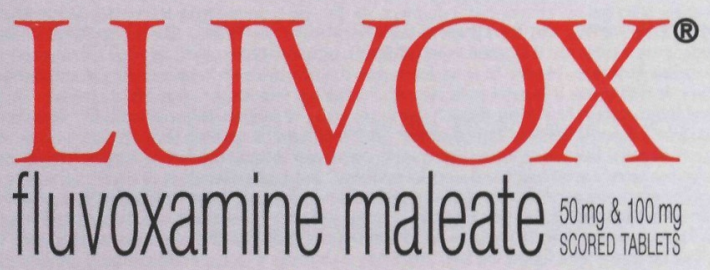

\section{A SELECTIVE SEROTONIN REUPTAKE INHIBITOR}

*Effectiveness not established beyond 10 weeks in controlled trials tParameters occurring $\geq 1 \%$ with fluvoxamine maleate. 